\title{
Clinical, Functional, and Radiographic Benefits of Longterm Adalimumab Plus Methotrexate: Final 10-year Data in Longstanding Rheumatoid Arthritis
}

\author{
Edward C. Keystone, Désirée van der Heijde, Arthur Kavanaugh, Hartmut Kupper, \\ Shufang Liu, Benoît Guérette, and Neelufar Mozaffarian
}

\begin{abstract}
Objective. To examine the longterm effectiveness and safety of adalimumab in patients with longstanding rheumatoid arthritis (RA) and an inadequate response to methotrexate (MTX), and to assess the effect of a 1-year delay in initiation of combination therapy.

Methods. DE019 was a 1-year randomized controlled trial (RCT) in which patients received adalimumab $20 \mathrm{mg}$ weekly, adalimumab $40 \mathrm{mg}$ every other week (eow), or placebo; all received concomitant MTX. Patients completing the RCT could receive open-label adalimumab $40 \mathrm{mg}$ eow + MTX for an additional 9 years. Clinical, functional, and radiographic outcomes were assessed using composite measures of disease activity (e.g., American College of Rheumatology responses, 28-joint Disease Activity Score with C-reactive protein, Simplified Disease Activity Index), Health Assessment Questionnaire-Disability Index, and the modified total Sharp score (mTSS), respectively. Results. Of the 619 patients randomized, 457 entered the open-label extension; 202 completed 10 years. At Year 10, patients demonstrated effective disease control and inhibition of radiographic progression. Differences in clinical and functional responses between adalimumab + MTX and placebo + MTX observed during the RCT became less apparent at Year 10. Still, patients who initially received adalimumab + MTX had significantly lower mean $\Delta$ mTSS at Year 10 compared with patients who initially received placebo + MTX. No new safety signals arose following up to 10 years of adalimumab + MTX exposure.

Conclusion. During up to 10 years of treatment with adalimumab + MTX, patients with longstanding RA experienced effective disease control with no change to the expected safety profile. A 1-year delay in receipt of adalimumab + MTX was associated with reduced effectiveness, suggesting that a window of opportunity to prevent irreversible damage exists even in a population with established RA. (First Release July 1 2013; J Rheumatol 2013;40:1487-97; doi:10.3899/ jrheum.120964)
\end{abstract}

Key Indexing Terms:

ADALIMUMAB

\section{METHOTREXATE RANDOMIZED CONTROLLED TRIAL \\ RHEUMATOID ARTHRITIS}

Rheumatoid arthritis (RA) is a progressive disease affecting the joints, ultimately leading to disability and comorbidity in affected patients. The extent to which current RA treatments modify the course of disease varies, and most patients, in particular those with longstanding disease, require continued, longterm therapy to abate further erosive damage. Despite such a requirement, information surrounding the longterm effectiveness and safety of treatment options is limited.

Methotrexate (MTX) is generally prescribed as a
From the University of Toronto, Toronto, Ontario, Canada; Leiden University Medical Center, Leiden, The Netherlands; University of California San Diego, La Jolla, California, USA; AbbVie Deutschland GmbH \& Co KG, Ludwigshafen, Germany; and AbbVie Inc., North Chicago, Illinois, USA.

AbbVie Inc. sponsored the study (NCT00195702). Dr. Keystone has received consulting fees or other remuneration from, and served on advisory boards on behalf of, AbbVie, AstraZeneca, Biotest, BMS, Centocor, Genentech, Merck, Nycomed, Pfizer, Roche and UCB, has received research grants from AbbVie, Amgen, AstraZeneca, BMS, Centocor, Genzyme, Merck, Novartis, Pfizer, Roche and UCB, and has speaker honoraria agreements with AbbVie, Amgen, BMS, Janssen, Merck, Pfizer, Roche and UCB. Dr. van der Heijde has received consulting fees or other remuneration from AbbVie, Amgen, AstraZeneca, BMS, Centocor, Chugai, Eli-Lilly, GSK, Merck, Novartis, Otsuka, Pfizer, Roche, Sanofi-Aventis, Schering-Plough, UCB, and Wyeth, and is the director of Imaging Rheumatology bv. Dr. Kavanaugh has received consulting fees or other remuneration and research grants from AbbVie, Amgen, Astra-Zeneca, BMS, Celgene, Centocor-Janssen, Pfizer, Roche, and UCB. Drs. Kupper, Liu, Guérette, and Mozaffarian are employees of AbbVie Inc. and may hold stock or stock options.

E.C. Keystone, $M D$, University of Toronto; D. van der Heijde, $M D, P h D$, Leiden University Medical Center; A. Kavanaugh, MD, University of California San Diego; H. Kupper, MD, AbbVie Deutschland GmbH \& Co KG; S. Liu, PhD; B. Guérette, PhD; N. Mozaffarian, MD, PhD, AbbVie Inc.

Address correspondence to Dr. E.C. Keystone, The Rebecca MacDonald Centre for Arthritis and Autoimmune Disease, Joseph and Wolf Lebovic Building, 2nd Floor, 60 Murray Street, Toronto, ON M5T 3L9, Canada. E-mail: edkeystone@mtsinai.on.ca

Full Release Article. For details see Reprints/Permissions at jrheum.org Accepted for publication May 9, 2013. 
first-line disease-modifying antirheumatic drug (DMARD) to treat active $\mathrm{RA}^{1,2,3}$. Randomized controlled clinical trials have established that the addition of anti-tumor necrosis factor (TNF) agents to MTX therapy in patients with an inadequate response to MTX results in significant improvements in clinical, radiographic, and functional outcomes $4,5,6,7,8,9,10,11$. Current recommendations for patients with poor prognostic factors suggest treatment with MTX for 3 to 6 months before considering the addition of biologic DMARD therapy ${ }^{12}$, but some rheumatologists continue MTX for longer periods before considering the addition of biologic therapy ${ }^{13,14}$. For patients early in the course of disease ( $<3$ years' duration), there may be a window of opportunity (estimated to be at least 6 months) during which the timely addition of anti-TNF therapy to MTX-inadequate responders can result in optimal therapeutic responses ${ }^{15}$. However, a 2-year delay appears to exceed this window, resulting in an inability to improve outcomes ${ }^{16}$. Whether such an opportunity exists for patients with more established disease remains unclear.

Our analysis describes the final 10-year clinical, functional, and radiographic outcomes for patients with longstanding, active RA and an inadequate response to MTX who received up to 10 years of combination therapy with adalimumab + MTX. We discuss the longterm effect of a 1-year delay in the addition of adalimumab to existing MTX therapy, and we present the overall safety profile following up to 10 years of exposure to adalimumab + MTX.

\section{MATERIALS AND METHODS}

Study design and patients. The methodology and primary results for the 1-year, double-blind phase of DE019, a randomized, placebo-controlled trial of adalimumab in patients with moderate to severe RA who demonstrated an inadequate response to MTX, have been published ${ }^{6}$, as have results from the first 4 years of the open-label extension ${ }^{17}$. The study protocol and informed consent forms were approved by the local institutional review boards (USA) or research committees (Canada) at each participating site. The study was conducted in accord with the principles of the Declaration of Helsinki and Good Clinical Practice.

Enrolled patients were adults $\geq 18$ years of age with a diagnosis of moderate to severely active RA (1987 revised criteria) despite at least 3 months' treatment with MTX (12.5-25 mg/week). They also met the following key inclusion criteria: tender joint count $\geq 9$ out of 68 assessed (TJC68), swollen joint count $\geq 6$ out of 66 assessed (SJC66), C-reactive protein $(\mathrm{CRP}) \geq 1.0 \mathrm{mg} / \mathrm{dl}$, and positive for rheumatoid factor or at least 1 bony erosion. Patients were excluded from entry to the study if they had a history of human immunodeficiency virus or active infection with listeria or tuberculosis (TB), any ongoing chronic or active infection requiring hospitalization, treatment with intravenous antibiotics within 30 days or oral antibiotics within 14 days prior to the screening visit, joint surgery in the assessed joints within 2 months prior to screening, treatment with a biologic or other investigational drug within 30 days or 5 half-lives of the agent prior to screening evaluation, treatment with any anti-TNF agent, or history of lymphoma, leukemia or any other malignancy in the past 5 years, with the exception of successfully treated nonmetastatic basal cell or squamous cell carcinomas of the skin and/or localized carcinoma in situ of the cervix ${ }^{6}$.

Patients were randomized 1:1:1 to receive subcutaneous doses of adali- mumab $20 \mathrm{mg}$ weekly $(\mathrm{n}=212)$, adalimumab $40 \mathrm{mg}$ every other week (eow; $\mathrm{n}=207)$, or placebo $(\mathrm{n}=200)$; all patients received concomitant MTX therapy. Patients completing the 1-year randomized controlled trial were eligible to enroll in a 9-year open-label extension in which they received adalimumab $40 \mathrm{mg}$ eow + MTX

Clinical and functional assessments. Clinical assessments included the 28-joint Disease Activity Score with CRP (DAS28-CRP), the Simplified Disease Activity Index (SDAI), and American College of Rheumatology $50 \%, 70 \%$, and $90 \%$ (ACR50, ACR70, and ACR90) responses. Low disease activity (LDA) was defined as DAS28-CRP $<3.2$. Clinical remission was defined as DAS28-CRP $<2.6$ or SDAI $\leq 3.3$. Functionality was assessed using the Health Assessment Questionnaire-Disability Index (HAQ-DI), with normal function defined as HAQ-DI $<0.5$. Individual ACR components were also evaluated: TJC68, SJC66, patient assessment of pain, patient global assessment, physician global assessment, and CRP levels.

Radiographic assessments. Two readers, blinded to patient and sequence, assessed Year 10 radiographs of the hands and feet using the modified total Sharp score (mTSS; range 0-380) for joint erosion (range 0-220) and joint space narrowing (JSN; range 0-160). For this analysis, radiographs from baseline, Year 1, Year 8, and Year 10 (or early termination, if occurring after Year 9) were evaluated in a blinded fashion. Radiographic nonprogression was defined as $\Delta \mathrm{mTSS} \leq 0.5$ at Year 10. In addition, minimal radiographic progression was defined as $\Delta \mathrm{mTSS} \leq 5$ at Year 10 (average of $\leq 0.5 / \mathrm{yr}$, over $10 \mathrm{yrs})^{18}$.

Comprehensive disease control: combination of clinical, functional, and radiographic outcomes. Comprehensive disease control was defined by clinical LDA (DAS28-CRP < 3.2) or remission (DAS28-CRP < 2.6) plus normal function (HAQ-DI $<0.5$ ) plus radiographic nonprogression $(\Delta \mathrm{mTSS}$ $\leq 0.5)$ or minimal radiographic progression $(\Delta \mathrm{mTSS} \leq 5)$ at Year 10 .

Safety. Treatment-emergent adverse events (TEAE) were defined as any adverse event (AE) with an onset on or after the date of first adalimumab injection through 70 days after the last adalimumab injection. AE were coded using the Medical Dictionary for Drug Regulatory Affairs (MedDRA) system organ class and MedDRA-preferred terms (version 13.1). AE were assessed throughout the study and summarized for all patients exposed to adalimumab as both the number and percentage of patients affected and the number of events per 100 patient-years (E/100-PY) of adalimumab exposure. Severe and serious AE, including serious infections, malignancies, TB, and death, were summarized. Any TEAE leading to study discontinuation was also summarized.

Statistical analyses. This posthoc analysis evaluated the longterm effectiveness and safety of adalimumab + MTX using data as observed (i.e., all patients with data at a given visit were included with no imputation for missing values). Effectiveness measures were analyzed overall as well as by initial treatment assignment to evaluate the clinical, functional, and radiographic effect of a 1-year delay in the addition of adalimumab to MTX monotherapy. In this analysis, patients who received 1 year of placebo + MTX before entering the open-label extension are referred to as the "delayed combination therapy group," and patients who received adalimumab + MTX throughout the study are referred to as the "initial combination therapy group." Differences in response rates as well as clinical and functional outcomes between the initial and delayed combination therapy groups were assessed through generalized estimating equations, which analyzed the repeated responses at Years 1-10. Area under the curve (AUC) analyses were used to assess cumulative differences in DAS28-CRP and HAQ-DI between the initial and delayed combination therapy groups over the 10-year period. Radiographic progression was assessed in patients with mTSS assessments available at baseline and Year 10 (or at early termination, if occurring after Year 9). Differences in mean $\Delta$ mTSS between treatment groups were assessed using a constrained longitudinal data analysis ${ }^{19}$, which adjusts for the observed baseline difference in estimating treatment effects. Observed changes in mTSS were plotted as cumulative probabilities both for the entire 10-year period (from baseline) and for the

Personal non-commercial use only. The Journal of Rheumatology Copyright (c) 2013. All rights reserved. 
9-year open-label period (from Year 1). A Kolmogorov-Smirnov test was used to assess the equality of the cumulative distribution functions. A standardized mortality ratio (SMR) was calculated and defined as the ratio of observed deaths to expected deaths based on World Health Organization age-, sex-, and country-specific mortality tables (years 1997-2006).

\section{RESULTS}

Patients. Of the 619 patients randomized, 202 (32.6\%, including 66, 80, and 56 from the initial adalimumab $20 \mathrm{mg}$ weekly + MTX, adalimumab $40 \mathrm{mg}$ eow + MTX, and placebo + MTX groups, respectively) completed 10 years of therapy and had available study data (Figure 1); a total of 203 patients (191 Year 10 completers +12 early terminators) with mTSS data available at baseline and beyond Year 9 were considered to be radiographic completers. The development of $\mathrm{AE}$ was the primary reason for early discontinuation, accounting for $22.5 \%$ of enrolled patients, although most $\mathrm{AE}$ were not serious and $38.1 \%(\mathrm{n} / \mathrm{N}=53 / 139)$ occurred during the 1-year double-blind period. Numerically greater proportions of patients from the initial placebo + MTX group (n/N = 31/200, 23 of whom discontinued during the double-blind period) discontinued owing to lack of efficacy than from either adalimumab + MTX group $(\mathrm{n} / \mathrm{N}=16 / 212$ and 17/207 for the adalimumab $20 \mathrm{mg}$ weekly and adalimumab $40 \mathrm{mg}$ eow groups, respectively).

Baseline demographic and disease characteristics for the 10 -year radiographic completers were typical of a population with longstanding RA: most patients were female, with a mean age of 54 years, mean disease duration 11 years, mean DAS28-CRP 5.6. They had accrued significant amounts of radiographic damage (mean mTSS was 51), with low function (mean HAQ-DI was 1.4; Table 1). Baseline characteristics for all randomized patients $(\mathrm{n}=$ $619)$ and patients who received at least 1 injection of adalimumab during blinded or open-label therapy $(\mathrm{n}=553$; safety population) have been described ${ }^{6,17}$. Characteristics were generally similar between the 10-year radiographic completers and the overall intent-to-treat population, with the exception that the radiographic completers appeared to represent a younger subset of the overall randomized population.

Overall longterm effectiveness. Following up to 10 years of adalimumab + MTX treatment, patients demonstrated effective disease control and inhibition of radiographic progression. At Year 10,64.2\%, 49.0\%, and $17.6 \%$ of patients achieved ACR50, ACR70, and ACR90 responses, respectively. Mean DAS28-CRP was 2.6, with $74.1 \%$ achieving an LDA state at Year 10. Remarkably, 59.0\% and $33.2 \%$ achieved DAS28-CRP and SDAI remission states, respectively. Functional outcomes were similarly improved; from baseline to Year 10, mean HAQ-DI was reduced by $50 \%$ (improvement from 1.4 to 0.7 ) and $42.2 \%$ of patients achieved normal functionality. Further, radiographic

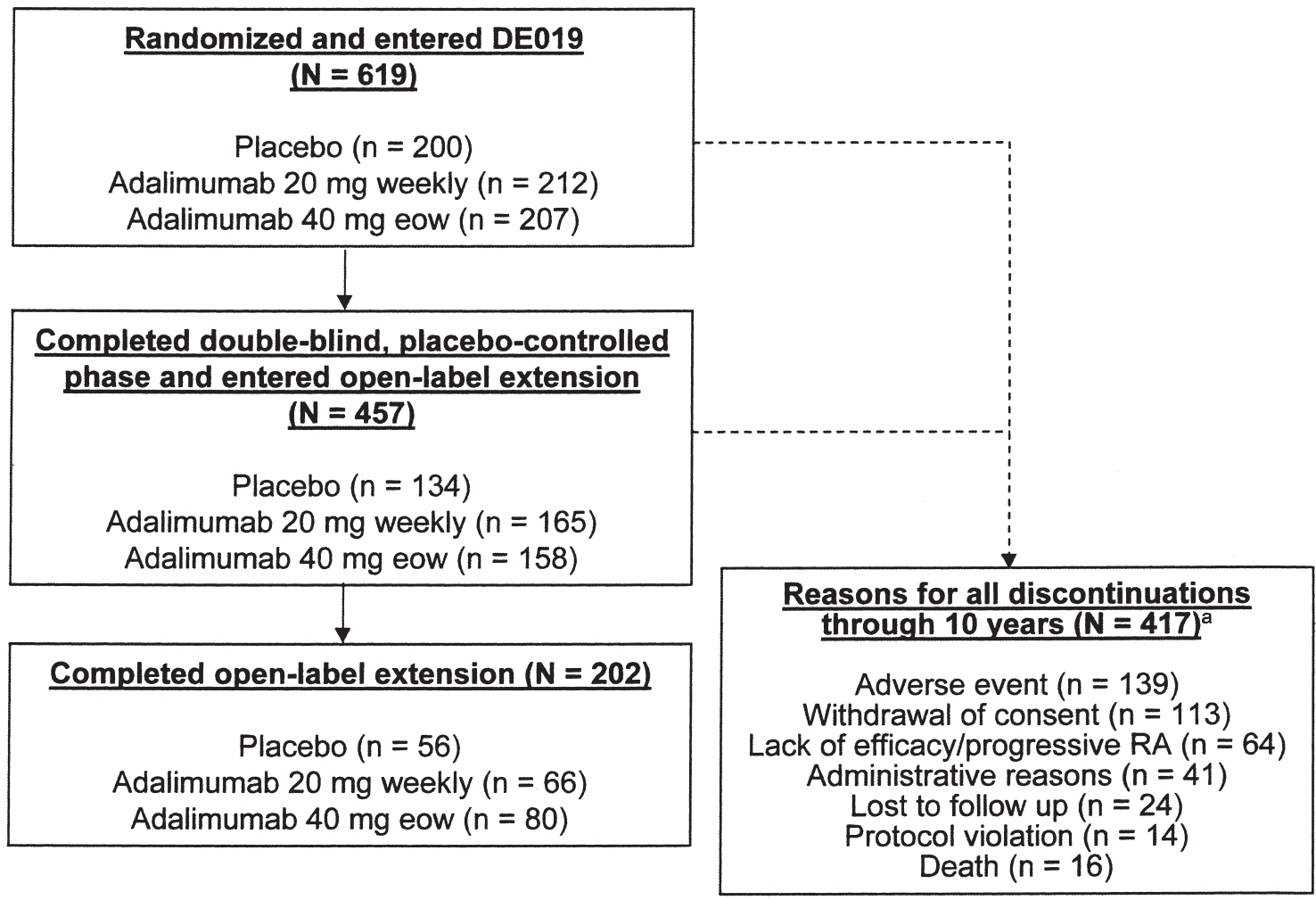

Figure 1. Patient disposition through 10 years in DE019, a 1-year randomized controlled trial of adalimumab and methotrexate (MTX). ${ }^{\text {ancludes }} 6$ patients from the placebo + MTX arm who completed the double-blind phase but did not enter the open-label period. eow: every other week.

Personal non-commercial use only. The Journal of Rheumatology Copyright @ 2013. All rights reserved. 
Table 1. Baseline demographic and baseline/Year 1 disease characteristics: 10-year radiographic completers. All values are mean $\pm \mathrm{SD}$, unless otherwise indicated.

\begin{tabular}{|c|c|c|c|c|c|c|}
\hline $\begin{array}{l}\text { Baseline } \\
\text { Characteristic }\end{array}$ & \multicolumn{2}{|c|}{$\begin{array}{c}\text { ADA } 20 \mathrm{mg} \\
\text { Weekly + MTX, } \\
\text { n }=70\end{array}$} & $\begin{array}{r}\text { iitial ADA + } \\
\text { ADA } \\
\text { Eow }+ \\
\mathrm{n}=\end{array}$ & $\begin{array}{l}\text { ITX } \\
0 \mathrm{mg} \\
\text { MTX, } \\
79\end{array}$ & \multicolumn{2}{|c|}{$\begin{array}{c}\mathrm{PBO}+\mathrm{MTX} \\
\mathrm{n}=54\end{array}$} \\
\hline Age, yrs & \multicolumn{2}{|c|}{$55.1 \pm 9.6$} & \multicolumn{2}{|c|}{$53.8 \pm 11.3$} & \multicolumn{2}{|c|}{$53.8 \pm 9.9$} \\
\hline Women, n (\%) & \multicolumn{2}{|c|}{$53(75.7)$} & \multicolumn{2}{|c|}{$57(72.2)$} & \multicolumn{2}{|c|}{$38(70.4)$} \\
\hline Rheumatoid factor-positive, & \multicolumn{2}{|c|}{$55(78.6)$} & \multicolumn{2}{|c|}{$65(82.3)$} & \multicolumn{2}{|c|}{$50(92.6)$} \\
\hline Duration of RA, yrs & \multicolumn{2}{|c|}{$11.1 \pm 9.4$} & \multicolumn{2}{|c|}{$11.0 \pm 8.1$} & \multicolumn{2}{|c|}{$11.2 \pm 8.2$} \\
\hline Baseline DMARD use, $\mathrm{n}$ & \multicolumn{2}{|c|}{$70(100)$} & \multicolumn{2}{|c|}{79 (100) } & \multicolumn{2}{|c|}{$54(100)$} \\
\hline Baseline oral corticosteroid us & \multicolumn{2}{|c|}{ e,n (\%) $31(44.3)$} & \multicolumn{2}{|c|}{$27(34.2)$} & \multicolumn{2}{|c|}{$29(53.7)$} \\
\hline Characteristic & Baseline & Year 1 & Baseline & Year 1 & Baseline & Year 1 \\
\hline DAS28-CRP, range $0-10$ & $5.6 \pm 0.8$ & $3.3 \pm 1.1$ & $5.6 \pm 0.7$ & $3.3 \pm 1.0$ & $5.6 \pm 0.9$ & $4.4 \pm 1.4$ \\
\hline $\mathrm{CRP}, \mathrm{mg} / \mathrm{dl}$ & $1.5 \pm 1.2$ & $1.0 \pm 0.5$ & $1.9 \pm 1.8$ & $0.9 \pm 0.6$ & $1.5 \pm 1.4$ & $1.2 \pm 0.9$ \\
\hline TJC (0-68 joints) & $26.3 \pm 11.8$ & $6.8 \pm 8.2$ & $25.0 \pm 10.9$ & $8.5 \pm 9.9$ & $27.9 \pm 13.8$ & $15.3 \pm 13.6$ \\
\hline SJC (0-66 joints) & $19.1 \pm 8.7$ & $6.0 \pm 7.4$ & $19.1 \pm 9.0$ & $6.2 \pm 7.6$ & $20.0 \pm 10.9$ & $12.8 \pm 10.7$ \\
\hline HAQ-DI (range, 0-3) & $1.4 \pm 0.6$ & $0.6 \pm 0.6$ & $1.3 \pm 0.6$ & $0.6 \pm 0.6$ & $1.4 \pm 0.6$ & $1.0 \pm 0.7$ \\
\hline PGA (100 mm VAS) & $61.7 \pm 14.4$ & $16.8 \pm 15.0$ & $60.1 \pm 17.0$ & $16.1 \pm 14.4$ & $61.3 \pm 19.1$ & $34.7 \pm 23.4$ \\
\hline PaGA (100 mm VAS) & $46.2 \pm 21.5$ & $19.3 \pm 19.4$ & $49.0 \pm 18.8$ & $16.0 \pm 15.6$ & $49.2 \pm 22.7$ & $37.3 \pm 27.1$ \\
\hline Pain (100 mm VAS) & $49.4 \pm 21.5$ & $18.7 \pm 16.5$ & $54.3 \pm 19.7$ & $19.4 \pm 17.8$ & $52.2 \pm 23.6$ & $37.5 \pm 26.1$ \\
\hline mTSS (range, 0-380) & $53.5 \pm 55.7$ & $53.0 \pm 54.8$ & $52.9 \pm 52.5$ & $51.7 \pm 51.8$ & $45.0 \pm 41.2$ & $46.8 \pm 41.9$ \\
\hline JE (range, 0-220) & $26.1 \pm 29.0$ & $25.4 \pm 28.2$ & $27.7 \pm 27.7$ & $26.5 \pm 27.3$ & $21.9 \pm 20.4$ & $22.5 \pm 20.6$ \\
\hline JSN (range, 0-160) & $27.4 \pm 28.5$ & $27.6 \pm 28.2$ & $25.3 \pm 26.7$ & $25.2 \pm 26.4$ & $23.1 \pm 23.8$ & $24.4 \pm 24.4$ \\
\hline
\end{tabular}

a Patients enrolled in DE019 received ongoing MTX therapy. ADA; adalimumab; MTX: methotrexate; eow: every other week; PBO: placebo; RA: rheumatoid arthritis; DMARD: disease-modifying antirheumatic drug; DAS28: 28-joint disease activity score; CRP: C-reactive protein; TJC: tender joint count; SJC: swollen joint count; HAQ-DI: Health Assessment Questionnaire-Disability Index; PGA: physician's global assessment; VAS: visual analog scale; PaGA: patient's global assessment; mTSS: modified total Sharp score; JE: joint erosion score; JSN: joint space narrowing score.

progression was minimal during this longterm study, with a mean change from baseline to Year 10 in mTSS of 2.8 units (annual progression rate $\sim 0.3$ units/year).

Nearly half of the 10-year radiographic completers (44.8\%) had undetectable radiographic progression following up to 10 years of adalimumab + MTX therapy. Comprehensive disease control (DAS28-CRP $<3.2+$ HAQ-DI $<0.5+\Delta$ mTSS $\leq 0.5$ ) was achieved by $21.2 \%$ of patients. This number decreased only slightly to $20.2 \%$ when remission (DAS28-CRP < 2.6) was substituted for the clinical component, suggesting that disease activity state did not necessarily limit a patient's ability to achieve comprehensive disease control. Further, substantial proportions of patients were able to reduce or eliminate MTX and/or oral corticosteroid use (MTX: $33.2 \%$ and 9.4\% reduced and eliminated, respectively; oral corticosteroid: $13.7 \%$ and $62.9 \%$ reduced and eliminated, respectively), while retaining comparable longterm clinical outcomes (data not shown).

Effect of delayed treatment with adalimumab + MTX. Patients randomized to the placebo + MTX group received adalimumab only after entering into the open-label extension, resulting in a 1-year delay of combination therapy. The delayed combination therapy group enabled a comparison of longterm outcomes with patients who received adalimumab + MTX from the start of the study (the initial combination therapy group). Because the longterm effectiveness outcomes were largely comparable between the adalimumab $20 \mathrm{mg}$ weekly + MTX and adalimumab 40 mg eow + MTX populations (Figures 2A, 2B, and 2C), only the adalimumab $40 \mathrm{mg}$ eow + MTX population (the initial combination therapy group) was used for comparison to the placebo + MTX population (the delayed combination therapy group). The significant clinical and functional differences observed at a mean level at Year 1 in the randomized population [DAS28-CRP $=3.4$ and 4.5 and HAQ-DI $=0.8$ and 1.1 (both $\mathrm{p}<0.001$ ), for the initial and delayed combination therapy groups, respectively] were largely resolved following an additional 9 years of open-label adalimumab + MTX treatment [DAS28-CRP = 2.4 and $2.7(p=0.15)$; HAQ-DI $=0.7$ and $0.8(p=0.33)$ for initial and delayed combination therapy groups, respectively]. However, cumulative disease activity and functional impairment, as measured by DAS28-CRP and HAQ-DI, respectively, over the 10-year period, were greater in patients receiving delayed versus initial combination therapy [DAS28-CRP: mean AUC $=1648$ vs 1439 ( $\mathrm{p}=$ 0.007); HAQ-DI: mean AUC $=419$ vs $321(\mathrm{p}=0.06)]$. 
A



B



ADA 20 mg weekly+MTX, N=67

ADA $40 \mathrm{mg}$ eow+MTX, $\mathrm{N}=81$

C



Figure 2. Clinical, functional, and radiographic responses at Year 10 in the initial adalimumab (either $20 \mathrm{mg}$ weekly or $40 \mathrm{mg}$ eow) + MTX groups. After Year 1 (panel C, vertical broken line), all patients received open-label adalimumab $40 \mathrm{mg}$ eow + MTX. A. ACR50/70/90 responses. B. DAS28-CRP LDA < 3.2, DAS28-CRP remission < 2.6, SDAI remission $\leq 3.3$, and normal functionality (HAQ-DI < 0.5). C. Mean $\triangle \mathrm{mTSS}$ from baseline. ADA: adalimumab; MTX: methotrexate; eow: every other week; ACR: American College of Rheumatology; DAS28: 28-joint Disease Activity Score; CRP: C-reactive protein; SDAI: Simplified Disease Activity Index; HAQ-DI: Health Assessment Questionnaire-Disability Index; mTSS: modified total Sharp score. 
Similarly, statistically greater ACR50, ACR70, and ACR90 response rates were seen in patients who received initial combination therapy compared with patients in whom combination therapy was delayed for 1 year (Figure 3A). Interestingly, statistically greater numbers of swollen and/or tender joints persisted through 10 years of therapy in the delayed combination therapy group (Figure 3B), perhaps explaining the lower ACR50/70/90 responses over time. The proportions of patients achieving DAS28-CRP LDA, DAS28-CRP remission, and SDAI remission were maintained through 10 years in both groups; however, with the exception of SDAI remission, patients in the delayed combination therapy group did not achieve these disease activity outcomes in the same proportions as patients who received adalimumab + MTX from the start of the study (Figure 3C). At Year 10, 46\% of patients in the initial combination therapy group and $33 \%$ of patients in the delayed combination therapy group met the HAQ-DI $<0.5$ criterion, although the curves over time were not significantly different ( $p=0.14$; Figure 3D). Differences between initial and delayed combination therapy groups were also apparent in the pain and patient global assessments, but the physician global assessment and CRP measurements were comparable over the 10-year period (Figures 4A, 4B, 4C, and 4D).

The percentages of patients with radiographic nonprogression $(\Delta \mathrm{mTSS} \leq 0.5)$ at Year 1 were significantly greater for patients who received initial combination therapy $(83 \%$; $67 / 81$ patients) compared with those who received delayed combination therapy $(46 \% ; 25 / 54$ patients; $\mathrm{p}<0.001)$. At Year 10 (following 9 years of open-label adalimumab + MTX treatment for all patients), the percentages of patients with radiographic nonprogression were no longer statistically different $[51 \%$ (40/79 patients) for initial combination therapy vs $39 \%$ (21/54 patients) for delayed combination therapy $(\mathrm{p}=0.18)$ ], with comparable proportions having radiographic nonprogression in both groups (roughly 50\%) during the open-label period. Similar results were observed for the percentages of patients with minimal radiographic progression $[\Delta \mathrm{mTSS} \leq 5$ over 10 years: $77 \%$ vs $65 \%$ for initial and delayed combination therapy groups, respectively

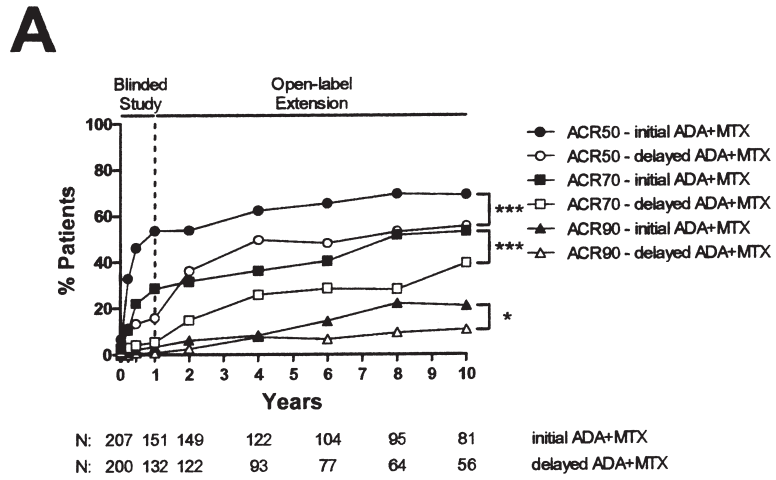

B

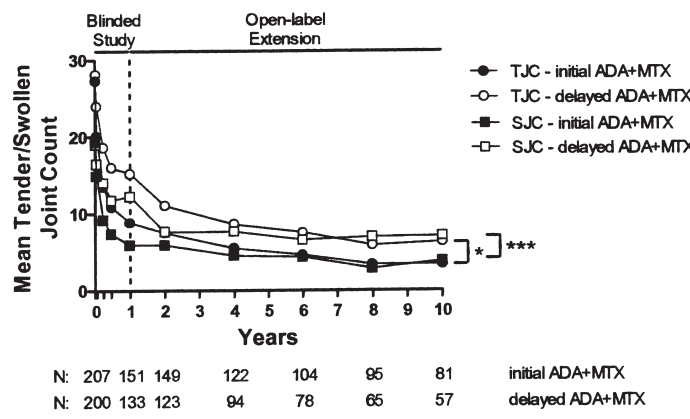

C

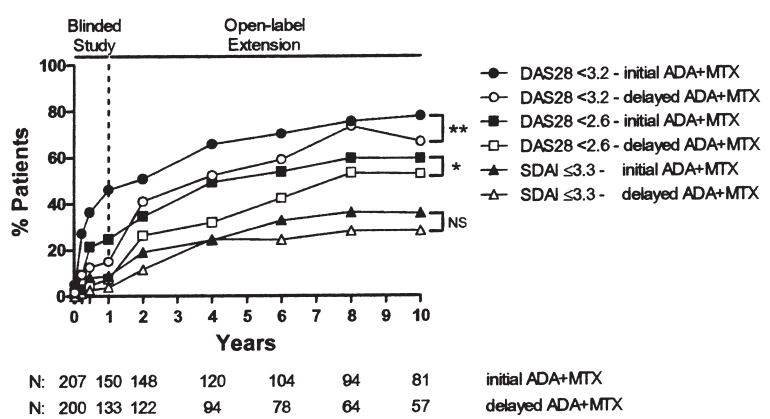

D



Figure 3. Clinical and functional responses through up to 10 years of treatment with adalimumab + MTX. Patients in the initial combination therapy group received adalimumab + MTX from the start of the study, and patients in the delayed combination therapy group received placebo + MTX during Year 1. After Year 1 (vertical broken line), all patients received open-label adalimumab $40 \mathrm{mg}$ eow + MTX. A. ACR50/70/90 responses. B. Mean TJC68 and SJC66. C. DAS28-CRP LDA $<3.2$, DAS28-CRP remission $<2.6$, and SDAI remission $(\leq 3.3)$. D. Normal physical function (HAQ-DI $<0.5)$. Statistically significant $* * * \mathrm{p}<0.001, * * \mathrm{p}<0.01$, and $* \mathrm{p}<0.05$ for differences between initial and delayed combination therapy groups from generalized estimating equations. NS (nonsignificant) indicates $\mathrm{p} \geq 0.05$. ACR: American College of Rheumatology; ADA: adalimumab; DAS28-CRP: 28-joint Disease Activity Score with C-reactive protein; eow: every other week; HAQ-DI: Health Assessment Questionnaire-Disability Index; LDA: low disease activity; MTX: methotrexate; SDAI: Simplified Disease Activity Index; SJC66: swollen joint count out of 66 assessed joints; TJC68: tender joint count out of 68 assessed joints.

Personal non-commercial use only. The Journal of Rheumatology Copyright @ 2013 . All rights reserved. 
A



B



D

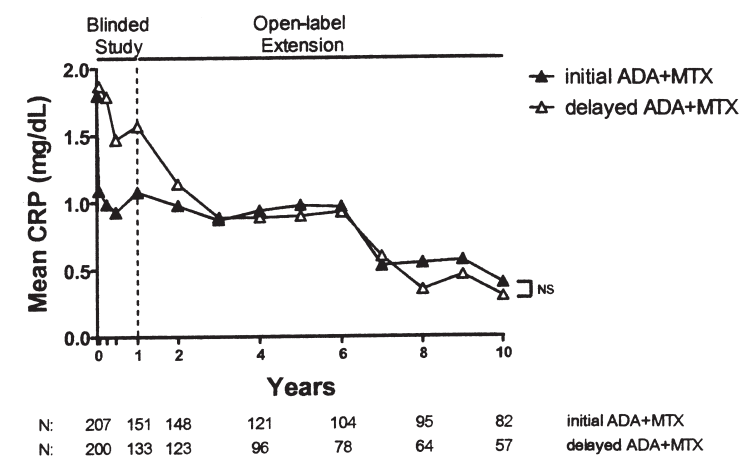

Figure 4. Clinical responses over time. Patients in the initial combination therapy group received adalimumab 40 mg eow + MTX throughout the study and patients in the delayed combination therapy group received placebo + MTX during Year 1. After Year 1 (vertical broken line), all patients received open-label adalimumab $40 \mathrm{mg}$ eow + MTX. A. Mean patient's assessment of pain (mm). B. Mean patient's global assessment (mm). C. Mean physician's global assessment (mm). D. Mean CRP (mg/dl). Statistically significant $* * p<0.01$ and $* \mathrm{p}<0.05$ for differences between initial and delayed combination therapy groups from generalized estimating equations. NS (nonsignificant) indicates $\mathrm{p} \geq 0.05$. ADA: adalimumab; MTX: methotrexate; CRP: C-reactive protein.

$(\mathrm{p}=0.12)]$. Still, the initial combination therapy group had significantly lower mean $\triangle$ mTSS compared with the delayed combination therapy group following 10 years of treatment [mean $\Delta$ mTSS (mTSS) $=0.7$ (53.6) vs 6.2 (51.2); $\mathrm{p}=0.002$; Figure 5A], a result that was driven by the extent of damage accrued during the randomized portion of the study [i.e., Year 1 ; mean $\Delta$ mTSS (mTSS) $=-1.3(51.7)$ vs 1.9 (46.8); $\mathrm{p}<0.001]$ and the higher residual number of swollen joints observed in the delayed combination therapy group. When the 9-year open-label period was analyzed as a separate treatment period (i.e., when the "baseline" mTSS score was set to the mTSS value at Year 1 for each group), the difference in radiographic change over 9 years of open-label adalimumab + MTX therapy was no longer significant. However, radiographic progression remained numerically lower for the initial combination therapy group [mean $\triangle$ mTSS $=2.0$ vs 4.3 for the initial and delayed combination therapy groups, respectively $(\mathrm{p}=0.22)]$. Similarly, when the mTSS scores at study start and Year 1 were used as baselines for the initial and delayed combi- nation therapy groups, respectively, there were no differences in the yearly progression rate $(p=0.19)$.

Among patients who experienced radiographic progression $(\Delta \mathrm{mTSS}>0.5$ ) during the 10-year study, those who received initial combination therapy appeared to have less structural damage at Year 10 than those who received delayed combination therapy (Figure 5B). This difference appeared to persist even when only the 9-year open-label period was considered, although the cumulative distribution of patients in the initial and delayed combination therapy groups during this timeframe did not differ statistically $(\mathrm{p}=$ 0.95; Figure 5C). Irrespective of original treatment group, it was the joint space narrowing (JSN) component of the mTSS that appeared to drive the mean radiographic progression (Figure 5D).

At Year 10, significantly more patients in the initial combination therapy group achieved comprehensive disease control compared with patients who began combination therapy after a 1-year delay, regardless of whether the clinical target was DAS28-CRP LDA or remission (Figure 



C

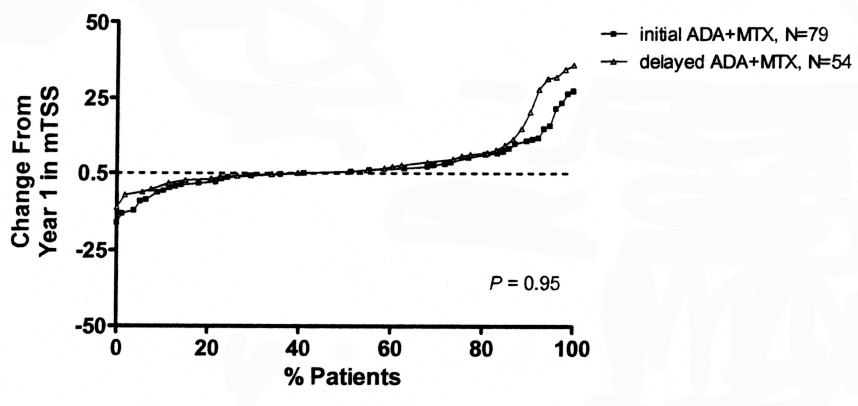

D



Figure 5. Ten-year radiographic completers: radiographic outcomes following up to 10 years of treatment with adalimumab + MTX. Patients in the initial combination therapy group received adalimumab + MTX from the start of the study, and patients in the delayed combination therapy group received placebo + MTX during Year 1. After Year 1, all patients received open-label adalimumab $40 \mathrm{mg}$ eow. A. Mean $\Delta \mathrm{mTSS}$ from baseline. B. Cumulative probability plot of $\triangle$ mTSS from baseline. P value from a Kolmogorov-Smirnov test indicates a statistical difference between the cumulative distribution functions. C. Cumulative probability plot of $\triangle \mathrm{mTSS}$ from beginning of the open-label extension. P value from a Kolmogorov-Smirnov test indicates no statistical difference between the cumulative distribution functions. D. Mean JE and JSN at Years 1, 8, and 10. ${ }^{a} \mathrm{p}=0.002$ for difference between initial and delayed ADA + MTX groups; ADA: adalimumab; eow: every other week; mTSS: modified total Sharp score; JE: joint erosion; JSN: joint space narrowing; MTX: methotrexate.

6). Significant differences also were observed when minimal radiographic progression $(\Delta \mathrm{mTSS} \leq 5 / 10$ yrs $)$ replaced the radiographic criterion in defining comprehensive disease control (data not shown).

Longterm safety. Cumulatively, there were 553 patients in DE019 who received at least 1 injection of adalimumab, with a mean exposure of 5.6 years, totaling 3089 patient-years of drug exposure. Overall, the safety profile was consistent with that observed during the 1-year randomized trial ${ }^{6}$, as well as with other trials of adalimumab in RA (Table 2). During this longterm study, the majority of patients exposed to adalimumab (96.9\%) experienced 1 or more $\mathrm{AE}$. The most frequently reported $\mathrm{AE}$ were upper respiratory tract infection, sinusitis, arthralgia, urinary tract infection, nasopharyngitis, hypertension, and bronchitis. Over the 10-year period, serious infections occurred at a rate of 4.3E/100-PY ( $\mathrm{n}=85$ patients), with pneumonia, cellulitis, lobar pneumonia, and bronchitis representing the most frequently reported. A total of 4 patients experienced fatal serious infections, with a mean age at infection onset of 76.6 years. These included a case of urosepsis, which occurred in a 77 -year-old woman about 66 days after the last adalimumab

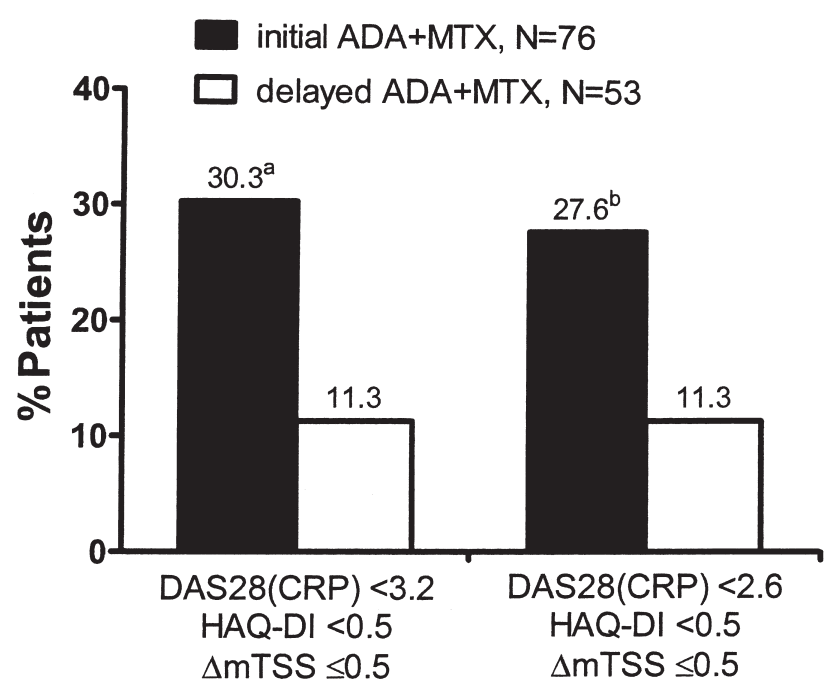

Figure 6. Percentage of patients with comprehensive disease control at Year 10. Statistically significantly different comprehensive disease (combined clinical + functional + radiographic) control between initial and delayed combination therapy treatment groups. ${ }^{\mathrm{a}} \mathrm{p}=0.01 ;{ }^{\mathrm{b}} \mathrm{p}=0.03$. ADA: adalimumab; MTX: methotrexate; DAS28-CRP: 28-joint Disease Activity Score with C-reactive protein; HAQ-DI: Health Assessment Questionnaire-Disability Index; mTSS: modified total Sharp score. 
Table 2. Overview of adverse events: all patients with at least 1 adalimumab injection ${ }^{\mathrm{a}}$.

\begin{tabular}{lcc}
\hline & $\mathrm{N}=553$, & $\mathrm{PY}=3089.2$ \\
& $\mathrm{n}(\%)$ & Events (E/100 PY) \\
\hline Any AE & $536(96.9)$ & $11,937(386.4)$ \\
Serious AE & $271(49.0)$ & $678(21.9)$ \\
AE leading to discontinuation & & \\
$\quad$ of study drug & $127(23.0)$ & $179(5.8)$ \\
Infectious AE & $448(81.0)$ & $2873(93.0)$ \\
$\quad$ Serious infectious AE & $85(15.4)$ & $133(4.3)$ \\
Opportunistic infection (excluding tuberculosis & \\
$\quad$ and oral candidiasis) & $8(1.4)$ & $10(0.3)$ \\
Tuberculosis & $2(0.4)$ & $2(<0.1)$ \\
Malignant AE (excluding NMSC & & \\
$\quad$ and lymphoma) & $30(5.4)$ & $34(1.1)$ \\
NMSC & $36(6.5)$ & $45(1.5)$ \\
Lymphoma & $5(0.9)$ & $6(0.2)$ \\
Demyelinating disease AE & $2(0.4)$ & $2(<0.1)$ \\
Injection site reaction & $115(20.8)$ & $258(8.4)$ \\
Hepatic-related AE & $86(15.6)$ & $165(5.3)$ \\
Death & $24(4.3)$ & $24(0.8)$ \\
& &
\end{tabular}

a Any AE with an onset date on or after the day of the first ADA injection through 70 days after the last ADA injection in Year 10. ${ }^{\mathrm{b}}$ Includes 6 deaths that were not treatment emergent (occurring $>70$ days after last adalimumab injection). PY: patient-years; AE: adverse event; NMSC: nonmelanoma skin cancer.

injection (Day 2965), a case of sepsis in a 76-year-old woman about 1 day after the last adalimumab injection (Day 492), a case of histoplasmosis in a 66-year-old man about 65 days after the last adalimumab injection (Day 1641), and a case of Escherichia sepsis/septic shock in a 75-year-old woman about 10 days after the last adalimumab injection (Day 116). Another 8 patients presented with opportunistic infections (0.3E/100-PY). They were oral fungal infection $(n=5$ patients), fungaemia ( $\mathrm{n}=1$ patient), disseminated histoplasmosis ( $\mathrm{n}=1$ patient), and mycobacterium avium complex infection $(\mathrm{n}=1$ patient). There were 2 cases of TB $(<$ $0.1 \mathrm{E} / 100-\mathrm{PY})$. Both patients with TB had normal chest radiographs and were purified protein derivative-negative at screening. Malignancies, excluding nonmelanoma skin cancer and lymphoma, occurred at a rate of 1.1E/100-PY ( $\mathrm{n}=30$ patients), of which breast cancer was the most frequently reported $(0.2 \mathrm{E} / 100-\mathrm{PY}, \mathrm{n}=6$ patients $)$. A total of 5 patients reported lymphoma (0.2E/100-PY), 2 patients had demyelinating disease (multiple sclerosis), and 2 patients had systemic lupus erythematosus-like syndrome.

There were 24 deaths during this 10-year study (18 were defined as a TEAE), 20 of which occurred during the 9-year open-label extension period. The treatment-emergent deaths not related to a serious infection included 3 cancers (metastatic gastric cancer, B-cell lymphoma, metastatic non-small cell lung cancer), 3 respiratory system events (2 pulmonary embolism, 1 interstitial lung disease), 2 injuries (head injury, multiple fractures), 2 cardiovascular events (acute myocardial infarction, cardiac arrest), and 4 other events (chemical poisoning, sudden death, death of unknown origin, intestinal infarction). The SMR was 0.77 (95\% CI $0.52,1.10)$, indicating that longterm exposure to adalimumab + MTX was not associated with an increase in mortality in this population.

\section{DISCUSSION}

The current treatment pattern for the effective management of RA is to treat aggressively until a sustained target of remission or at least LDA is achieved ${ }^{20}$. In many patients, particularly those with an inadequate response to DMARD therapy, target attainment will require supplemental therapy with a biologic DMARD, such as an anti-TNF agent. Although therapy may be successfully withdrawn in some patients with early RA who achieve an LDA state ${ }^{21,22}$, patients with longstanding RA will likely require longterm therapy. Longterm observations are therefore necessary to fully understand a particular treatment's benefit-risk profile. In this 9-year open-label extension of the 1-year randomized, controlled trial, DE019, we evaluated the effectiveness and safety of longterm therapy with adalimumab + MTX in patients with longstanding disease and an inadequate response to MTX. Treatment with the combination of adalimumab + MTX led to high proportions of patients experiencing effective disease control and a safety profile that was consistent with the known profile of adalimumab therapy. Further, although the delayed combination therapy group (i.e., patients randomized to placebo + MTX during the controlled trial) maintained their clinical responses through up to 9 years of subsequent combination therapy, longitudinal results showed a consistent pattern of higher responses in patients treated with adalimumab + MTX from the beginning of the study, suggesting that a window of opportunity for response to treatment exists even in an RA population with established disease.

Current recommendations for the treatment of RA state that remission is the primary goal ${ }^{20}$, and that LDA is an acceptable target for patients with longstanding disease who are refractory to treatment. Although patients enrolled in our study had extensive baseline joint damage, owing to the long duration of active disease and an inadequate response to standard DMARD therapy, nearly $60 \%$ of patients who completed 10 years of treatment achieved DAS28-CRP remission, with about one-third of 10-year completers fulfilling the more stringent SDAI remission criteria. Thus, clinical remission remains a possibility even for patients in this treatment-refractory population. Moreover, patients completing 10 years of treatment achieved excellent functional and radiographic outcomes, and about one-fifth achieved comprehensive disease control (which required combined attainment of clinical remission, normal physical functionality, and radiographic nonprogression).

Although the addition of adalimumab to MTX-inadePersonal non-commercial use only. The Journal of Rheumatology Copyright (c) 2013. All rights reserved. 
quate responders led to rapid improvements in clinical signs and symptoms regardless of the timing of addition (at study start or 1 year later), over the long term, the same level of responses typically were not observed for patients in whom adalimumab was delayed when compared with those who received adalimumab from the beginning of this 10-year study, resulting in a greater disease burden experienced by the delayed combination therapy population. Separation in treatment responses between the initial and delayed combination therapy groups was more apparent in measures associated with ongoing joint damage (e.g., swollen and tender joints, disability, and radiographic outcomes). The persistence of higher scores over time for each of these measures in the delayed combination therapy group may be reflective of the more significant damage accrued in the 1-year randomized trial during which patients received placebo + MTX. Because there are currently no treatment regimens capable of significantly reversing existing joint damage in most patients at such an advanced stage of disease, halting disease progression may be particularly important to prevent the loss of cartilage and soft tissues within the joint (as reflected in increasing JSN scores), because these tissue types are particularly difficult to repair. Indeed, over the long term, JSN appeared to be the primary driver of radiographic progression at a mean level in both groups, and this accrued to noticeably greater amounts in the delayed combination therapy group, a result likely explained by the more severe damage experienced through Year 1 and the higher cumulative disease activity observed through Year 10. Given the association of progression of JSN with physical disability and unfavorable employment status $^{23,24}$, these data support the idea that caution should be taken to avoid delaying treatment escalation in patients with ongoing disease. The accumulation of irreversible damage may preclude longterm success (e.g., restoration of physical function) of even the most efficacious of therapies.

Use of composite measures of disease activity, including measures of functional impairment and joint damage, as well as reduction of clinical disease activity, is emphasized in the treat-to-target recommendations ${ }^{12}$. When all 3 of these disease activity factors were combined into a single measure of comprehensive disease control, significantly more patients in the initial combination therapy group achieved this outcome at Year 10, regardless of whether the clinical criterion was based on LDA or remission and regardless of whether radiographic nonprogression was defined as an average of 0.5 year over the course of 10 years or as 0.5 over the entire period. Depending on the type of therapy administered, ongoing RA can be characterized by radiographic progression and irreversible disability if clinical remission is not sustained ${ }^{25}$. Thus, these results highlight the sustainability of adalimumab + MTX therapy for these 3 outcomes over the long term, which is an important treatment consideration in this chronic disease.
The safety profile observed following up to 10 years of treatment with adalimumab + MTX is consistent with previous adalimumab analyses both specific to RA and across other immune-mediated disorders ${ }^{26,27}$. In particular, the rate of serious infection for adalimumab + MTX-treated patients observed in this 10-year study is consistent with the published rates of 4.2-6.6 E/100-PY in patients receiving anti-TNF therapy in various RA registries ${ }^{28,29}$.

The major limitations of this analysis include the open-label study design and the observed data analysis, which can be biased by the patient population that continues in the study ${ }^{30}$. In this analysis, about one-third of enrolled patients maintained treatment with adalimumab + MTX for up to 10 years. Although this proportion represents only a fraction of the total enrolled population, this group was representative of the overall study population and of patients with longstanding disease.

Following up to 10 years of treatment with adalimumab + MTX, patients with longstanding RA experienced safe and highly effective disease control. Although improvements in clinical and functional outcomes were quickly achieved and maintained for up to 9 years of open-label therapy in both the initial and delayed combination therapy groups, patients in whom adalimumab + MTX was delayed for 1 year generally did not achieve the same levels of therapeutic responses as patients who received adalimumab + MTX from the start of the study. Moreover, cumulative radiographic damage at Year 10 was lower for patients who received initial versus delayed adalimumab + MTX therapy, suggesting that the delayed addition of an anti-TNF agent to existing, inadequate MTX monotherapy can have significant longterm repercussions, even in a population with established RA. Overall, these results highlight the ability of adalimumab + MTX combination therapy to yield longterm, comprehensive disease control in a population with longstanding RA.

\section{ACKNOWLEDGMENT}

The authors thank Dr. Michael Weinblatt (Boston, Massachusetts) for valuable discussions during the development of this report. Medical writing assistance in the development and revision of this report was provided by Benjamin Wolfe, PhD, of AbbVie Inc., and Cathryn Carter, MS, of Arbor Communications Inc., on behalf of AbbVie Inc.

\section{REFERENCES}

1. Aletaha D, Smolen JS. The rheumatoid arthritis patient in the clinic: Comparing more than 1,300 consecutive DMARD courses. Rheumatology 2002;41:1367-74.

2. Coury FF, Weinblatt ME. Clinical trials to establish methotrexate as a therapy for rheumatoid arthritis. Clin Exp Rheumatol 2010;5 Suppl 61:S9-12.

3. Weinblatt ME. Efficacy of methotrexate in rheumatoid arthritis. $\mathrm{Br}$ J Rheumatol 1995;Suppl 2:43-8.

4. Keystone E, Genovese MC, Klareskog L, Hsia EC, Hall S, Miranda $\mathrm{PC}$, et al. Golimumab in patients with active rheumatoid arthritis despite methotrexate therapy: 52-week results of the GO-FORWARD study. Ann Rheum Dis 2010;69:1129-35. 
5. Keystone E, Heijde D, Mason D Jr, Landewé R, Vollenhoven RV, Combe B, et al. Certolizumab pegol plus methotrexate is significantly more effective than placebo plus methotrexate in active rheumatoid arthritis: Findings of a fifty-two-week, phase III, multicenter, randomized, double-blind, placebo-controlled, parallel-group study. Arthritis Rheum 2008;58:3319-29.

6. Keystone EC, Kavanaugh AF, Sharp JT, Tannenbaum H, Hua Y, Teoh LS, et al. Radiographic, clinical, and functional outcomes of treatment with adalimumab (a human anti-tumor necrosis factor monoclonal antibody) in patients with active rheumatoid arthritis receiving concomitant methotrexate therapy: A randomized, placebo-controlled, 52-week trial. Arthritis Rheum 2004; 50:1400-11.

7. Lipsky PE, van der Heijde DM, St. Clair EW, Furst DE, Breedveld FC, Kalden JR, et al. Infliximab and methotrexate in the treatment of rheumatoid arthritis. Anti-Tumor Necrosis Factor Trial in Rheumatoid Arthritis with Concomitant Therapy Study Group. N Engl J Med 2000;343:1594-602.

8. Maini R, St. Clair EW, Breedveld F, Furst D, Kalden J, Weisman $\mathrm{M}$, et al. Infliximab (chimeric anti-tumour necrosis factor alpha monoclonal antibody) versus placebo in rheumatoid arthritis patients receiving concomitant methotrexate: A randomised phase III trial. ATTRACT Study Group. Lancet 1999;354:1932-9.

9. Nam JL, Winthrop KL, van Vollenhoven RF, Pavelka K, Valesini G, Hensor EM, et al. Current evidence for the management of rheumatoid arthritis with biological disease-modifying antirheumatic drugs: A systematic literature review informing the EULAR recommendations for the management of RA. Ann Rheum Dis 2010;69:976-86

10. Weinblatt ME, Keystone EC, Furst DE, Moreland LW, Weisman $\mathrm{MH}$, Birbara CA, et al. Adalimumab, a fully human anti-tumor necrosis factor alpha monoclonal antibody, for the treatment of rheumatoid arthritis in patients taking concomitant methotrexate: The ARMADA trial. Arthritis Rheum 2003;48:35-45.

11. Weinblatt ME, Kremer JM, Bankhurst AD, Bulpitt KJ, Fleischmann RM, Fox RI, et al. A trial of etanercept, a recombinant tumor necrosis factor receptor: $\mathrm{Fc}$ fusion protein, in patients with rheumatoid arthritis receiving methotrexate. N Engl J Med 1999;340:253-9.

12. Smolen JS, Aletaha D, Bijlsma JW, Breedveld FC, Boumpas D, Burmester G, et al. Treating rheumatoid arthritis to target: Recommendations of an international task force. Ann Rheum Dis 2010;69:631-7.

13. Guidelines for the management of rheumatoid arthritis: 2002 update. Arthritis Rheum 2002;46:328-46.

14. Schoels M, Aletaha D, Smolen JS, Bijlsma JW, Burmester G, Breedveld FC, et al. Follow-up standards and treatment targets in rheumatoid arthritis: Results of a questionnaire at the EULAR 2008. Ann Rheum Dis 2010;69:575-8.

15. Raza K, Saber TP, Kvien TK, Tak PP, Gerlag DM. Timing the therapeutic window of opportunity in early rheumatoid arthritis: Proposal for definitions of disease duration in clinical trials. Ann Rheum Dis 2012;71:1921-3.

16. van der Heijde D, Breedveld FC, Kavanaugh A, Keystone EC, Landewé R, Patra K, et al. Disease activity, physical function, and radiographic progression after longterm therapy with adalimumab plus methotrexate: 5-year results of PREMIER. J Rheumatol 2010;37:2237-46.

17. Keystone EC, Kavanaugh A, Weinblatt ME, Patra K, Pangan AL. Clinical consequences of delayed addition of adalimumab to methotrexate therapy over 5 years in patients with rheumatoid arthritis. J Rheumatol 2011;38:1552-62.
18. van der Heijde D, Simon L, Smolen J, Strand V, Sharp J, Boers M, et al. How to report radiographic data in randomized clinical trials in rheumatoid arthritis: Guidelines from a roundtable discussion. Arthritis Rheum 2002;47:215-8.

19. Liu GF, Lu K, Mogg R, Mallick M, Mehrotra DV. Should baseline be a covariate or dependent variable in analyses of change from baseline in clinical trials? Stat Med 2009;28:2509-30.

20. Smolen JS, Landewé R, Breedveld FC, Dougados M, Emery P, Gaujoux-Viala C, et al. EULAR recommendations for the management of rheumatoid arthritis with synthetic and biological disease-modifying antirheumatic drugs. Ann Rheum Dis 2010;69:964-75

21. Tanaka Y, Takeuchi T, Mimori T, Saito K, Nawata M, Kameda H, et al. Discontinuation of infliximab after attaining low disease activity in patients with rheumatoid arthritis: RRR (remission induction by Remicade in RA) study. Ann Rheum Dis 2010;69:1286-91.

22. van den Broek M, Klarenbeek NB, Dirven L, van Schaardenburg D, Hulsmans HM, Kerstens PJ, et al. Discontinuation of infliximab and potential predictors of persistent low disease activity in patients with early rheumatoid arthritis and disease activity score-steered therapy: Subanalysis of the BeSt study. Ann Rheum Dis 2011;70:1389-94.

23. Aletaha D, Funovits J, Smolen JS. Physical disability in rheumatoid arthritis is associated with cartilage damage rather than bone destruction. Ann Rheum Dis 2011;70:733-9.

24. Smolen JS, van der Heijde DM, Keystone EC, van Vollenhoven RF, Goldring MB, Guérette B, et al. Association of joint space narrowing with impairment of physical function and work ability in patients with early rheumatoid arthritis: Protection beyond disease control by adalimumab plus methotrexate. Ann Rheum Dis 2013;72:1156-62

25. van Tuyl LH, Felson DT, Wells G, Smolen J, Zhang B, Boers M. Evidence for predictive validity of remission on long-term outcome in rheumatoid arthritis: A systematic review. Arthritis Care Res 2010;62:108-17

26. Burmester GR, Panaccione R, Gordon KB, McIlraith MJ, Lacerda AP. Adalimumab: long-term safety in 23458 patients from global clinical trials in rheumatoid arthritis, juvenile idiopathic arthritis, ankylosing spondylitis, psoriatic arthritis, psoriasis and Crohn's disease. Ann Rheum Dis 2013;72:517-24.

27. Schiff MH, Burmester GR, Kent JD, Pangan AL, Kupper H, Fitzpatrick SB, et al. Safety analyses of adalimumab (HUMIRA) in global clinical trials and US postmarketing surveillance of patients with rheumatoid arthritis. Ann Rheum Dis 2006;65:889-94.

28. Curtis JR, Jain A, Askling J, Bridges SL Jr, Carmona L, Dixon W, et al. A comparison of patient characteristics and outcomes in selected European and U.S. rheumatoid arthritis registries. Semin Arthritis Rheum 2010;40:2-14.

29. Galloway JB, Hyrich KL, Mercer LK, Dixon WG, Fu B, Ustianowski AP, et al. Anti-TNF therapy is associated with an increased risk of serious infections in patients with rheumatoid arthritis especially in the first 6 months of treatment: Updated results from the British Society for Rheumatology Biologics Register with special emphasis on risks in the elderly. Rheumatology 2011;50:124-31.

30. Buch MH, Aletaha D, Emery P, Smolen JS. Reporting of long-term extension studies: Lack of consistency calls for consensus. Ann Rheum Dis 2011;70:886-90. 